\title{
The Dorsal Metacarpal Double Winged Advancement Flap: A Skin Graft Free Technique for Web Reconstruction in Congenital Simple Syndactyly
}

\author{
EHAB Z. AZZAM, M.D.; AHMED A. ZIDAN, M.D. and HOSSAM Y. EL-KAFRAWL, M.D.
}

The Department of Plastic Surgery, Faculty of Medicine, Alexandria University, Alexandria, Egypt

\begin{abstract}
Background: Local flabs and skin grafts are conventional methods of repair congenital syndactyly. Skin grafting for syndactyly repair is time consuming, has the potential risks of scar contracture and web creep and the results obtained are not always as functional and aesthetic as desired. In this article, we describe a graft-less surgical technique for web reconstruction in the correction of congenital simple syndactyly by using the dorsal metacarpal double winged advancement flab for web reconstruction with primary closure.
\end{abstract}

Patients and Methods: Between March 2016 and May 2017, 10 paediatric patients with 14 congenital simple sydactylies were reconstructed with the dorsal metacarpal double winged advancement flab. Complex syndactylies, Apert syndrome, Poland syndrome, traumatic and or post-burn syndactylies were excluded from the study. Operation time, intraoperative complications, early and late post-operative complications were followed-up clinically, and photographs were taken, including dorsal and volar views before and after the operation as well as at 2 month regular intervals for 1 year. The patient age ranged from 9 months to 48 months (median of 28.5 months). The minimum follow-up period was 12 months (range, 12-28 months; mean, 21.4 months).

Results: The mean operation time was approximately 78 minutes (65-90min.) Soft tissue defects were closed primarily without skin grafting in all cases. All the flabs survived completely without early complications such as infection, vascular compromise or delayed healing. No occurrence of long-term complications including web creep, flexion contractures, angulation deformity, or abnormal scarring formation were found during the follow-up period. Cosmetical and functional satisfactory outcomes were achieved in all cases without secondary revision.

Conclusion: The dorsal metacarpal double winged advancement flab is a graft-less solution for web spac reconstruction is non-tight congenital simple syndactyly.

Key Words: Dorsal - Metacarpal - Double winged - Flap Web - Reconstruction - Syndactyly.

\section{INTRODUCTION}

The term syndactyly derives from the Greek syn (together), and daktylos (finger), and refers to the clinical appearance of fingers which fail to separate into individual appendages which usually occurs during the sixth and eighth weeks of embryologic development [1]. Syndactyly is the most common congenital anomaly of the hands, with an incidence of 1 in 2000-3000 live births [2].

Syndactyly can be classified in several ways. Anatomically the syndactyly is either simple or complex, and complete or incomplete. Simple syndactyly involves only soft tissues whereas complex includes side-to-side bony fusion. When the adjacent digits are fused all to the finger-tip it is described as complete syndactyly, whilst the incomplete type refers to only partial union. Syndactyly can be an isolated finding or seen with other anomalies such as acrosyndactyly, clindodactyly, synostosis, cleft hand and polydactyl, or as a feature in several syndromes including Apert, Poland's, Pfeiffer, Jackson-Weiss and Holt-Oram [3].

The principles of syndactyly reconstruction involve separation of joined fingers early in life, creation of both cosmetically acceptable and functionally independent digits as well as a normal web well-adjusted to other interdigital webs. Many techniques for web space reconstruction have been described over the years [4]. Alternative techniques.

Introduced are a dorsal triangular flap [5,6], dorsally based rectangular flap, and a combination of interdigitating dorsal and palmar triangular flaps 
[7]. All these local flaps, however, require a skin graft to cover the resultant defect along the lateral wall of the web, especially around the bases of the fingers. However, use of skin grafts in addition of being time consuming, can cause problems such as donor site morbidity, graft loss, scarring, web creep, contractures, pigmentation issues, and, rarely, keloid formation $[\mathbf{8 , 9}]$.

Many authors have used the dorsal arterial network of the hand to provide skin flaps allowing skin graft-free reconstruction [10-12], including dorsal hexagonal advancement flap, pentagonal local flap and tri-lobed advancement flap. They allow primary closure of the skin defects without skin graft [13-15].

The goal of these methods is to improve web reconstruction in a tight syndactyly and facilitate direct closure by moving skin from the dorsal hand to the newly formed web and skin defects of the side walls. In this paper, we present our experience of the dorsal metacarpal double winged advancement flap in the reconstruction of the web space in congenital simple syndactyly of the hand.

\section{PATIENTS AND METHODS}

Between March 2016 and May 2017, 10 paediatric patients with 14 congenital simple sydactylies were reconstructed with the dorsal metacarpal double winged advancement flap Fig. (1) [16], including 8 complete and 6 incomplete congenital simple syndactylies of fingers. The syndactyly was unilateral in 6 patients and symmetrically bilateral in 4 patients. The ages ranged from 9 month to 4 years, with an average of 25.2 month.

\section{Exclusion crieteria:}

- Complex syndactylies.

- Apert syndrome, Poland syndrome.

- Traumatic and/or post-burn syndactylies.

\section{Surgical technique:}

Under general anaesthesia, the flap and skin incisions were outlined on the dorsal and palmar sides Figs. (2A,B). The marking begins by drawing a longitudinal line over the middle of each of the syndactylised digits. The joint levels are marked by horizontal lines both on the dorsal and on the palmar aspect of the digits. The proximal phalangeal region is divided into thirds. At the junction of the upper and middle third, a horizontal line is drawn. The hexagonal flap's distal angle is located in the middle of this line, which represents the distal vertex of the normal web space, while the proximal apex of the hexagonal flap started just proximal to the level of metacarpo-phalangeal joint. The dorsal flap was marked with width for proposed web space and an approximate 3:1 length-to-width ratio. From the middle portion of the flap, two equilateral triangular wings were extended to be inserted into the defects on the proximal side walls of the involved digits after their separation.

The finger incisions were designed in dorsal and volar zigzag pattern to fashion the triangular flaps for resurfacing of the fingers. The dorsal zigzag line begins distal to the apex of the vertex angle of the hexagonal flap creating triangular flaps with the mirror image, whereas the volar zigzag incisions start proximally over the proximal finger crease to create inter-digitating flaps. The lateral point of the triangular flaps reached the midline of the fingers to achieve enough coverage.

Incisions were then made along the pre-marked lines with no 15 surgical blade and use of magnifying loupes. Tourniquet ischaemia is achieved after only elevating the hand to keep the vessels full. This allowed easier identification of digital vasculature during surgical dissection. The dorsal flap was elevated over the para-tenon distally while the proximal subcutaneous tissues were dissected free to mobilize the flap distally. The deep soft tissues between the metacarpal heads were maintained as a vascular pedicle of the flap harbouring the perforators from the dorsal metacarpal arteries (Fig. 2C).

Caution was advised during the entire dissection procedure to minimize trauma to the perforators and to ensure viability of the winged flap.

Digital separation proceeds from distal to proximal and from dorsal to volar through the zigzag incisions. The proximal dissection was done with delicate protection to the neurovascular bundles and was restricted in bifurcation of the common digital artery which was carefully preserved. After all the flaps had been elevated, the tourniquet was deflated and the perfusion of the involved fingers and the flaps was confirmed. In general, defattening of the raised triangular flaps was performed to facilitate primary closure. The dorsal winged flap was advanced distally and volarly through the inter-digital space. The distal apex of the flap was sutured to an anchor-shaped incision at the palmar side and the two wings were inserted into the defects on the proximal sidewalls of the involved digits (Figs. 2D,E). The donor site of the dorsal flap was closed in a V-Y style (Fig. 2F). 
To avoid an inflammatory response from absorbable sutures during their degradation, we used non-absorbable 6-0 polypropylene sutures. At the end of the operation, the involved fingers were positioned in abduction with sterile gauze dressings. All patients were discharged on the following day after assessment of the vascularity of the flap and involved digits, followed by a change of dressing every week. The sutures were removed after two weeks and the dressings were permanently removed at 3 weeks. A splint was applied only for two weeks before the active range of motion of the fingers was commenced. Patients were followed-up clinically, and photographs were taken, including dorsal and volar views before and after the operation as well as at 2 month regular intervals for 1 year.

Operation time and intraoperative complications including compromised digital perfusion or neurovascular injury were recorded. Post-operative complications: Full or partial flap loss, infection or delayed healing were followed-up. Long-term evaluations included web creep, flexion contractures, degree of scarring, secondary angulation deformity, decreased range of motion, and need for reoperation.

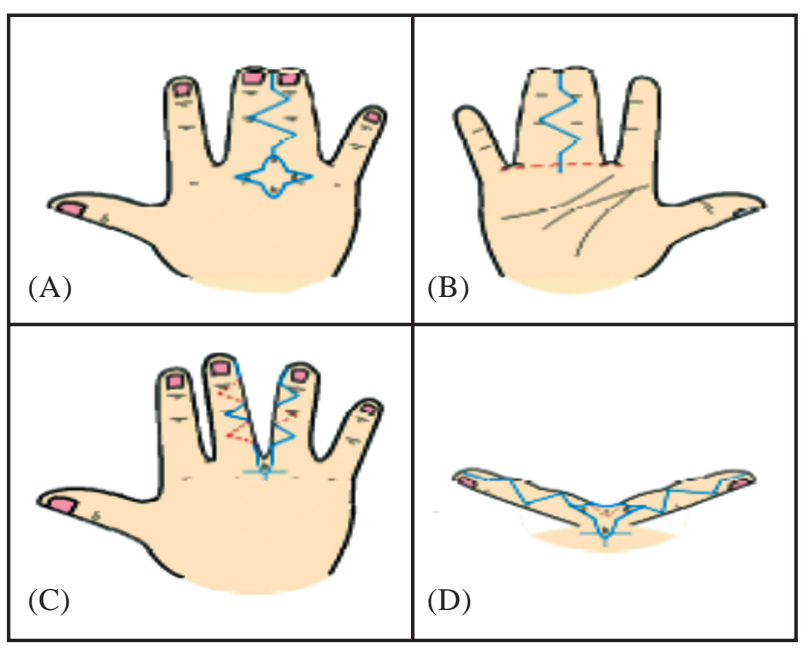

Fig. (1): Markings on both dorsal and palmar sides for incisions $(A, B)$. Donor site was closed in a V-Y style $(C, D)$.
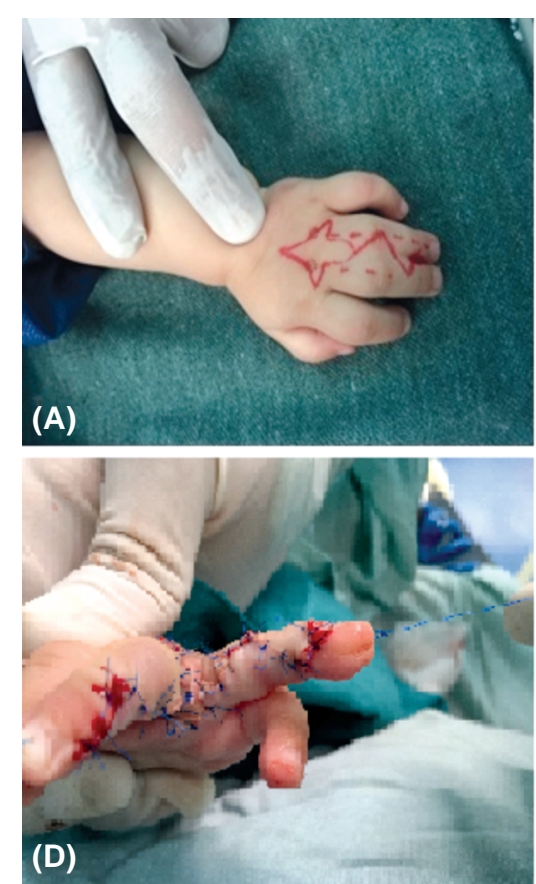
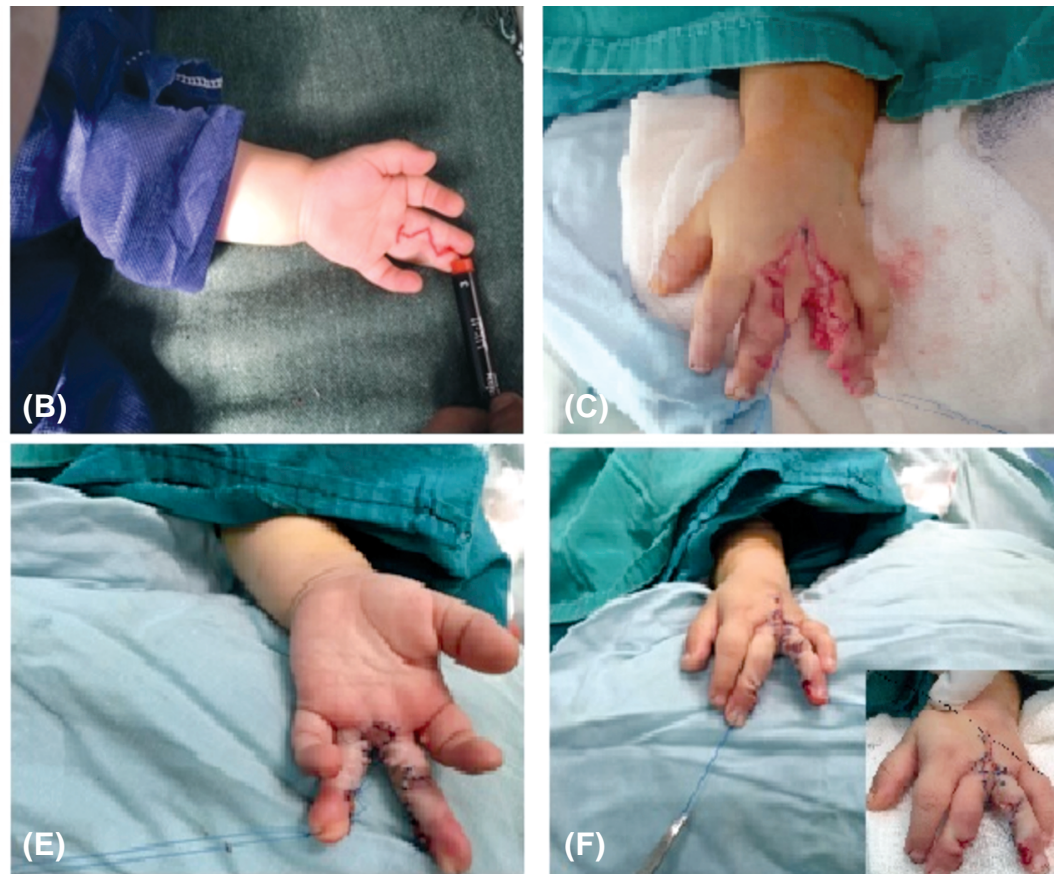

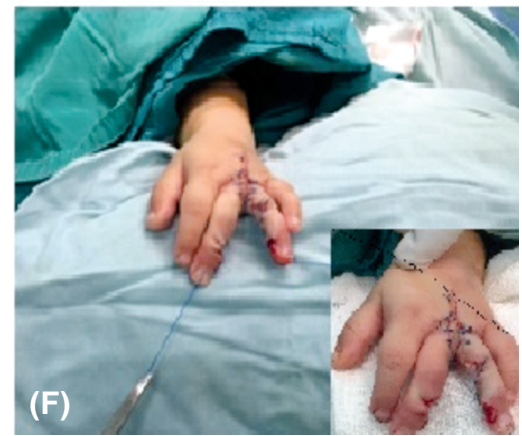

Fig. (2): Flap and skin incision were outlined on the dorsal and palmar sides (A,B). The dorsal double winged flap dissected and mobilized distally maintaining the deep soft tissues between the metacarpal heads intact $(\mathrm{C})$. The distal head of the double winged flap was sutured to the tip of palmar incision, and the two wings were inserted into the defects on the proximal sidewalls of the involved digits $(\mathrm{D}, \mathrm{E})$. The donor site on the dorsum of the hand was closed in a cross and V-Y style. (F). 
The evaluation on the results was done in accordance with the following protocol [17]:

Good result: Adequate interdigital space, similar to normal fingers with skin of normal appearance; possibility of superimposing one finger on another; flap placed during surgery is intact, absence of abnormal healing; and completely normal functioning of the fingers.

Fair result: Inadequate interdigital space, with abnormal appearance; difficulty in superimposing one finger on another; partial loss of the flap or interdigital skin; need for skin grafting; and abnormal healing.

Poor result: Absence or abnormality of interdigital space; impossibility of superimposing the released fingers; total loss of the flap; abnormal healing or need for skin grafting; and total loss of finger functioning.

\section{RESULTS}

Demographic criteria of the patients and clinical outcomes are shown in (Table 1).

Table (1): Demographic of the patients and clinical outcomes.

\begin{tabular}{|c|c|c|c|c|c|c|c|c|c|c|}
\hline $\begin{array}{l}\text { Pt. } \\
\text { (No.) }\end{array}$ & $\begin{array}{c}\text { Age } \\
\text { (months) }\end{array}$ & Sex & Location & $\begin{array}{l}\text { Involved } \\
\text { web }\end{array}$ & Type & $\begin{array}{l}\text { Op. time } \\
\text { (min.) }\end{array}$ & $\begin{array}{l}\text { Follow-up } \\
\text { period }\end{array}$ & $\begin{array}{l}\text { Early } \\
\text { Comp. }\end{array}$ & $\begin{array}{l}\text { Late } \\
\text { Comp. }\end{array}$ & $\begin{array}{c}\text { Evaluation } \\
\text { of results }\end{array}$ \\
\hline 1 & $26 \mathrm{~m}$ & M & Both hands & $4^{\text {th }}$ & Complete & 85 & 20 & No & No & Good \\
\hline 2 & $28 \mathrm{~m}$ & M & Left hand & $4^{\text {th }}$ & Complete & 85 & 16 & No & No & Good \\
\hline 3 & $9 m$ & $\mathrm{~F}$ & Left hand & $3^{\text {rd }}$ & Incomplete & 70 & 24 & No & No & Good \\
\hline 4 & $48 \mathrm{~m}$ & M & Right hand & $2^{\text {nd }}$ & Incomplete & 75 & 20 & No & No & Good \\
\hline 5 & $16 \mathrm{~m}$ & $\mathrm{~F}$ & Both hands & $3^{\text {rd }}$ & Incomplete & 65 & 12 & No & No & Good \\
\hline 6 & $32 \mathrm{~m}$ & $\mathrm{~F}$ & Left hand & $3^{\text {rd }}$ & Incomplete & 70 & 22 & No & No & Good \\
\hline 7 & $28 \mathrm{~m}$ & M & Both hands & $3^{\text {rd }}$ & Complete & 85 & 24 & No & No & Good \\
\hline 8 & $22 \mathrm{~m}$ & M & Right hand & $2^{\text {nd }}$ & Complete & 90 & 28 & No & No & Good \\
\hline 9 & $36 \mathrm{~m}$ & $\mathrm{~F}$ & Left hand & $4^{\text {th }}$ & Incomplete & 70 & 22 & No & No & Good \\
\hline 10 & $40 \mathrm{~m}$ & M & Both hands & $3^{\text {rd }}$ & Complete & 85 & 26 & No & No & Good \\
\hline
\end{tabular}

The male-to female ratio was six male patients $(60 \%)$ to four female patients $(40 \%)$. One patient was less than 1-year old (10\%), seven were between 1 and 3 years of age $(70 \%)$ and there were two patients over 3 years old $(20 \%)$. Six patients were unilaterally affected $(60 \%)$ while the remaining four patients $(40 \%)$ had symetrically bilateral syndactyly. From the 14 simple syndactiles, the third web was involved in 8 webs $(57.14 \%)$ with $4(28.57 \%)$ affecting the fourth web and $2(14.28 \%)$ affecting the second web.

All the 14 simple, (6 incomplete, and 8 complete) syndactiles in 10 patients were reconstructed with the present technique. The age group at the time of surgery ranged from 9 months to 48 months (median of 28.5 months). Intraoperative complications (poor perfusion of flaps and or neurovascular bundle injury) were not found during the operation. In all cases, the dorsal double winged advancement flaps were adequately perfused and sufficiently mobile to be transferred for reconstruction of the commissure. Post-operatively, there were no early complications such as hematoma, infection, or flap necrosis and complete wound healing was experienced in all cases within 2 weeks. The mean operative time was approximately 78 minutes (65-90 min.) After a minimum follow-up period of 12 months (range, 12-28 months; mean, 21.4 months), the reconstructed webs remained satisfactory. The appearance of the reconstructed web was similar to that of the adjacent normal webs in terms of skin quality, color as well as the dimension of the web and its dorso-palmar inclination. No patients developed flexion contractures, and all fingers were able to fulfil the main functions of flexion and abduction movement without revision surgery. On follow-up, all patients had a normal to hypopigmented scar in the donor site of the flap with supple pliability. The scar of the donor site was flat in all patients except one case who showed a mild hypertrophic scar which became flattened after $6 \mathrm{~m}$ with the use of silicone gel.

Figs. (3-6) show some results of this technique. 


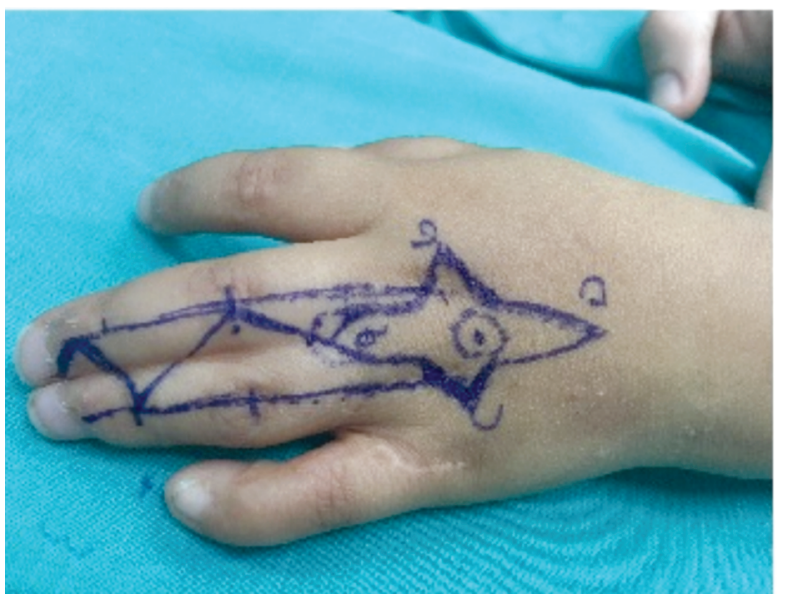

(A)

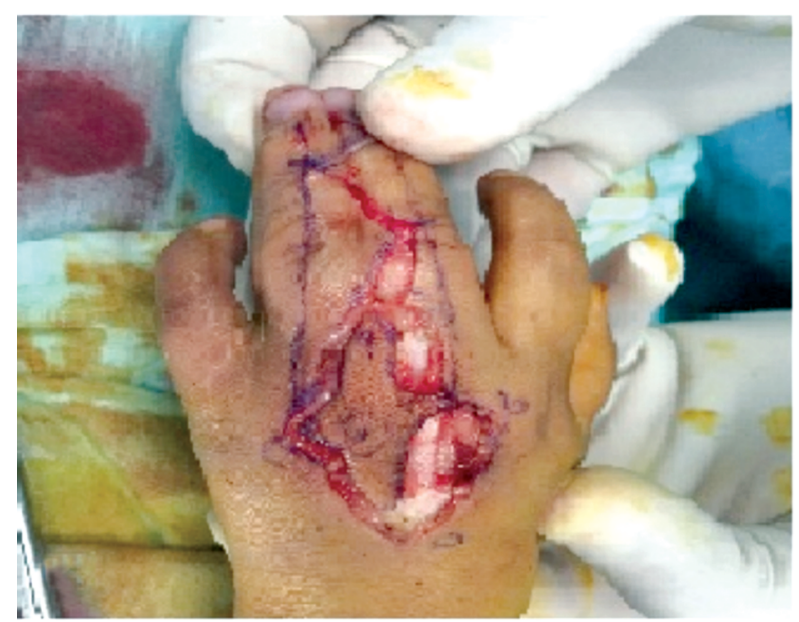

(C)

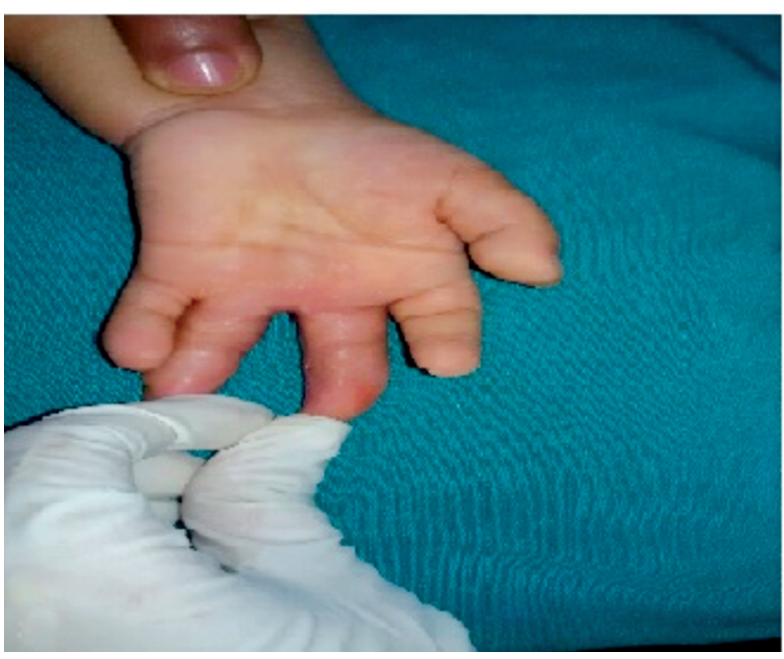

(E)

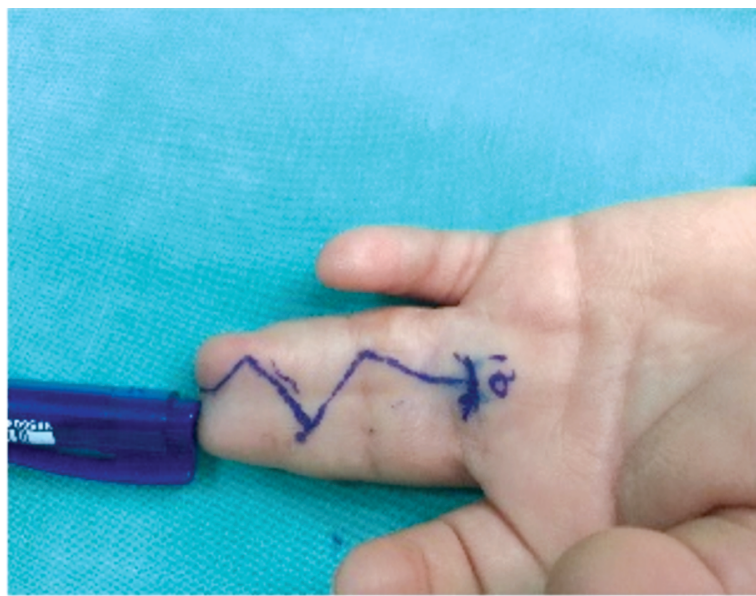

(B)

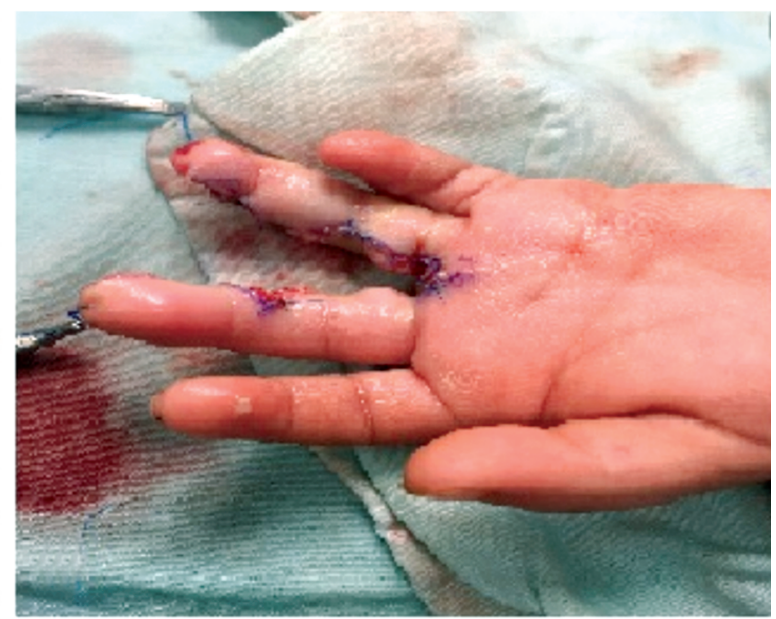

(D)

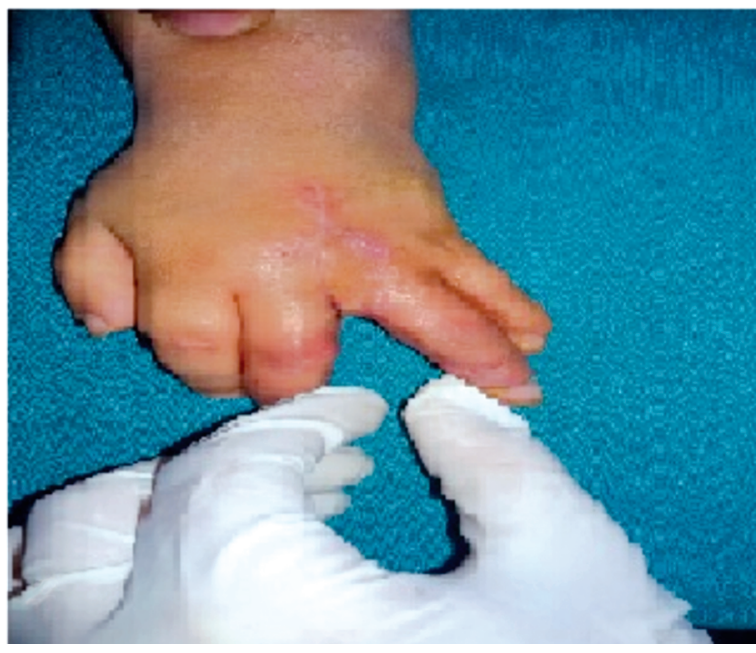

(F)

Fig. (3): Case 1: A 40 months-old male with complete syndactyly in the third web space of his left hand with the pre-operative markings of incisions of on both dorsal and palmar sides (A,B). Intra-operative dissection of the double winged flap (C). Immediately post-operative after separation of the involved digits and in-setting of the flaps (D). After six months with satisfactory clinical outcome, and normal function (E,F). 


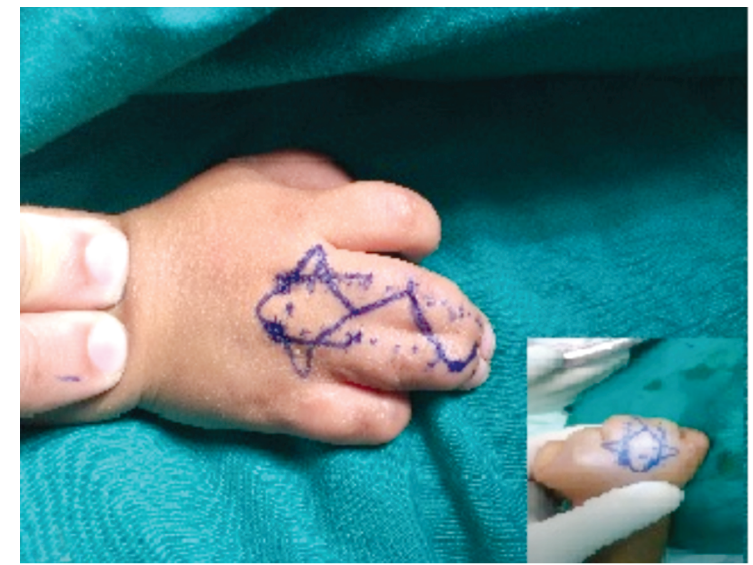

(A)

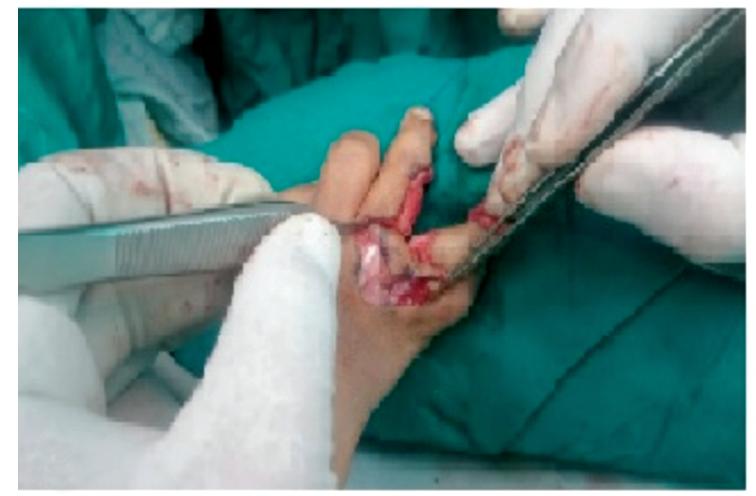

(C)

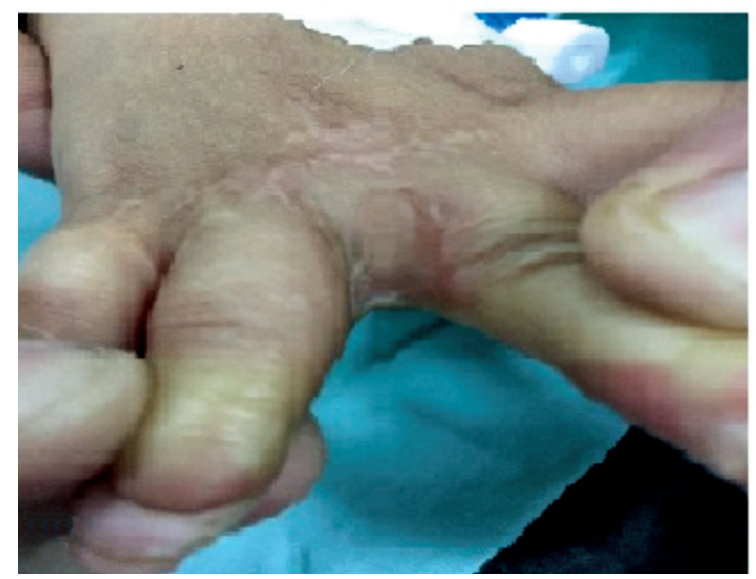

(E)

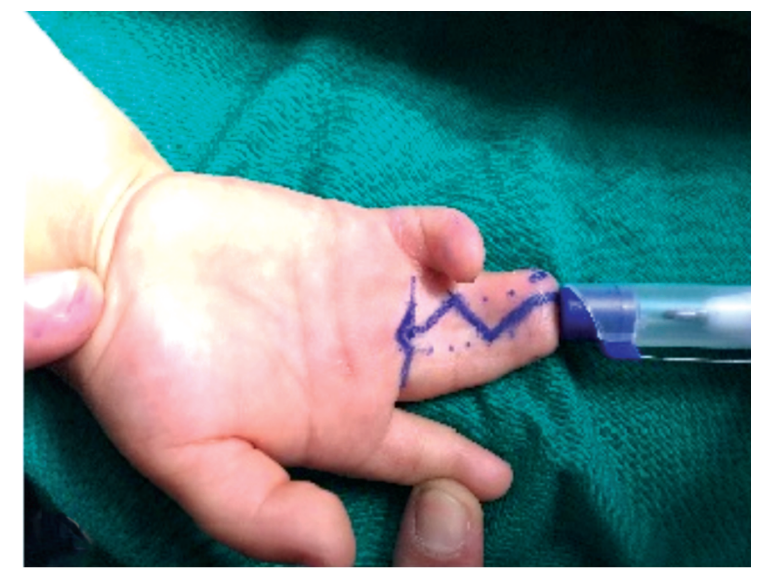

(B)

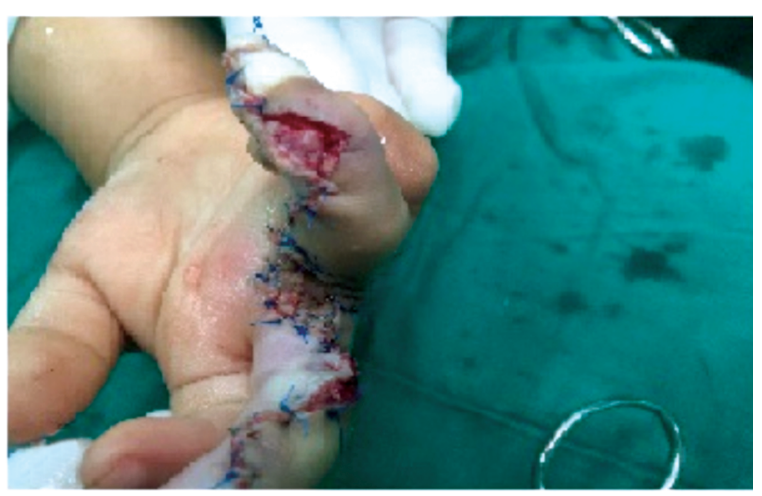

(D)

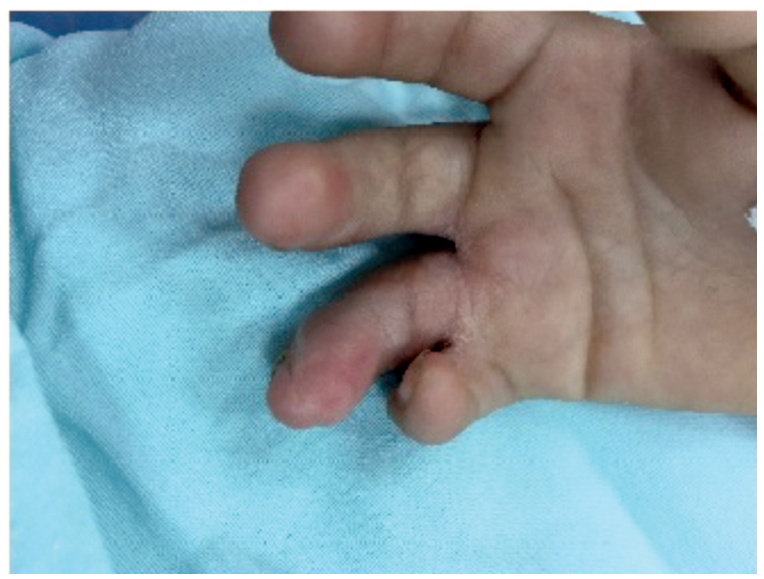

(F)

Fig. (4): Case 2: A 28 months old male with right complete simple syndactyly in the third web space of his right hand with the pre-operative markings of incisions of on both dorsal and palmar sides $(A, B)$ intraoperative dissection and in-setting of the double winged flap (C,D). After 18 months post-operative follow-up period with a satisfactory clinical outcome, with cosmetically normal web space and normal function (E,F). 


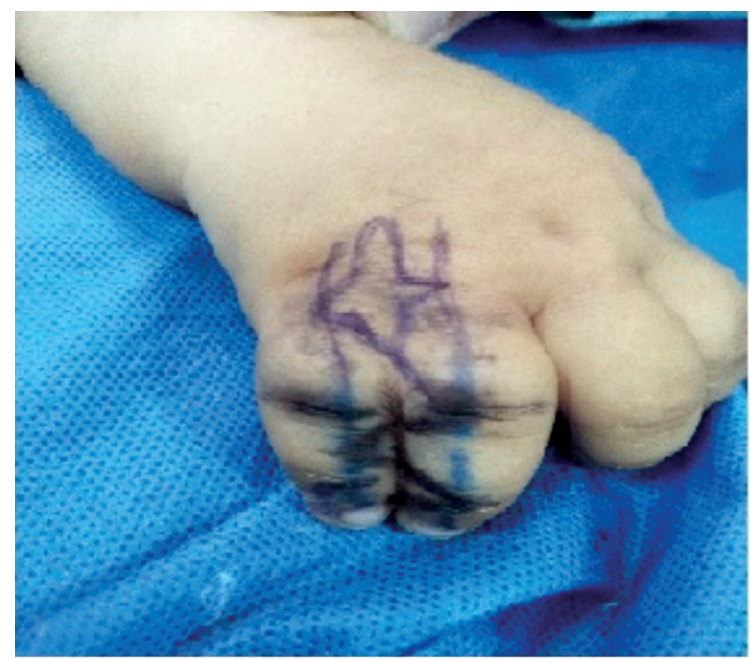

(A)

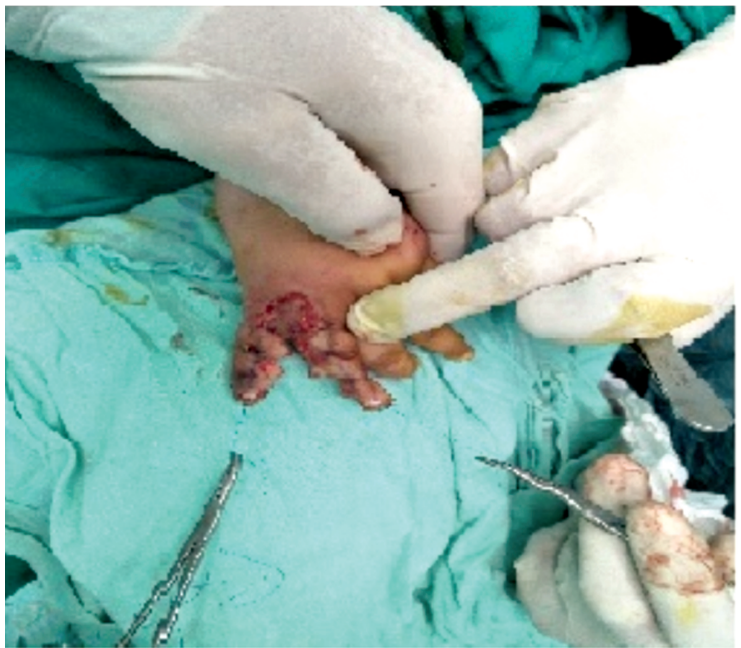

(C)

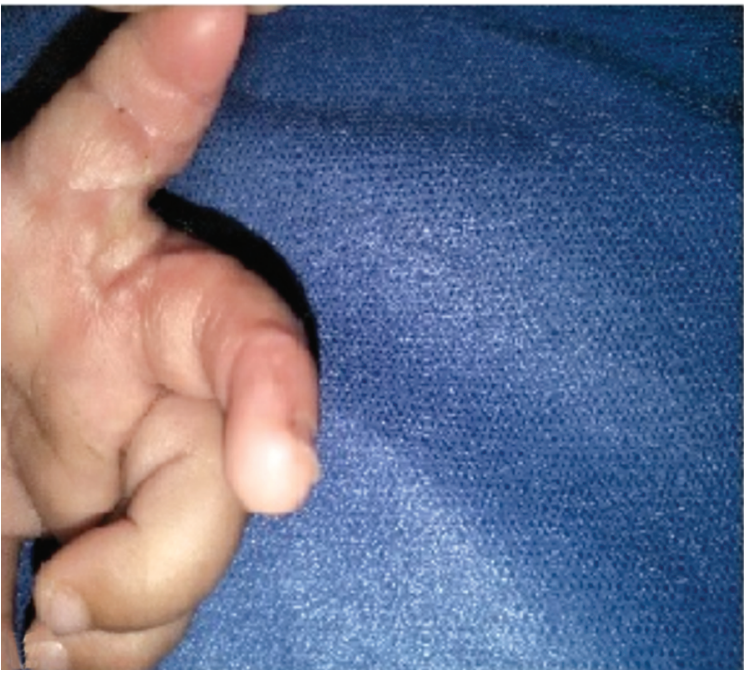

(E)

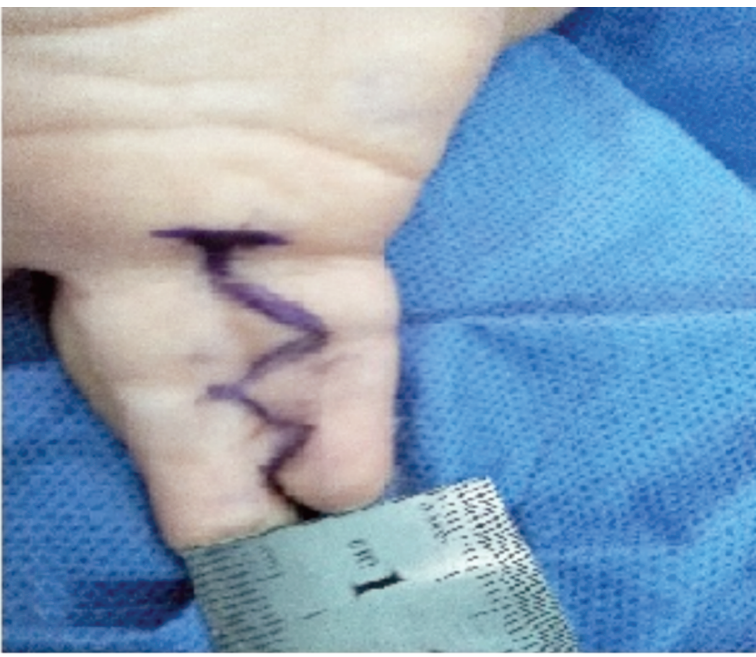

(B)

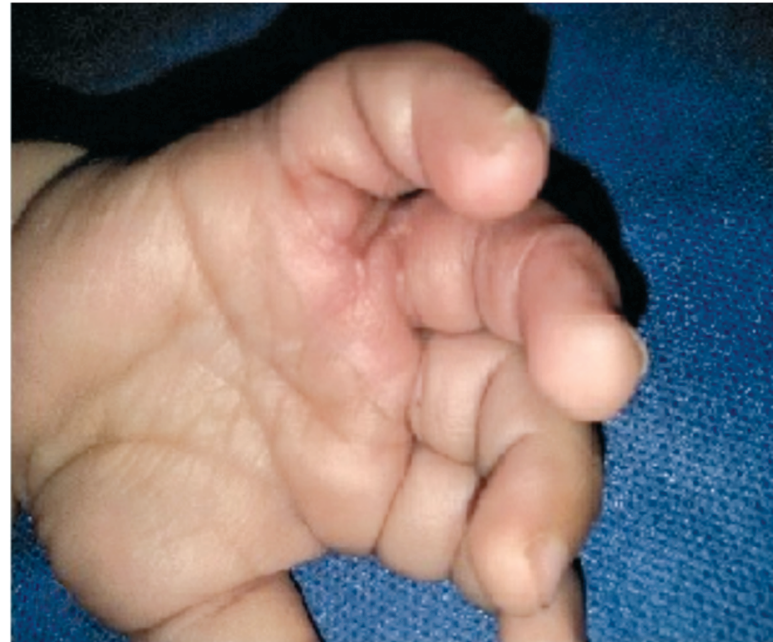

(D)

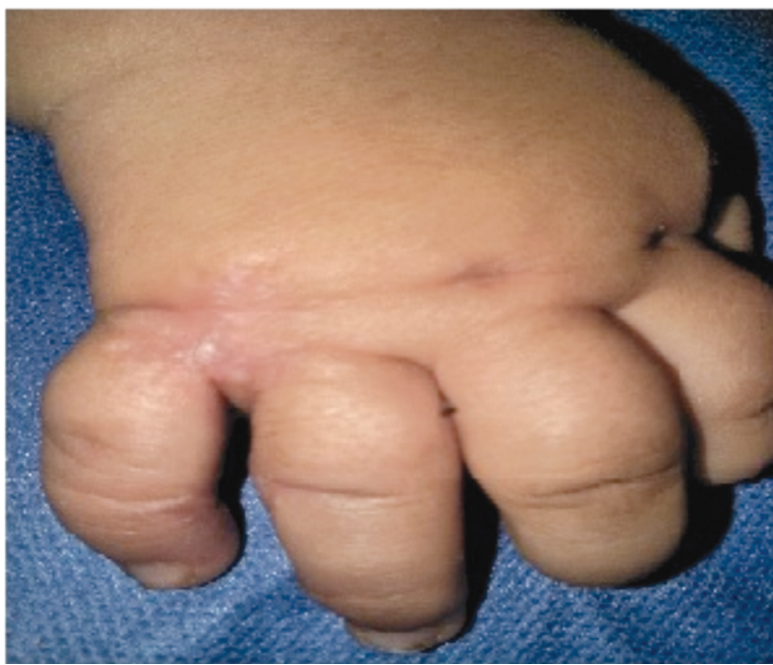

(F)

Fig. (5): Case 3: A 36 months old female with left simple incomplete congenital syndactyly in the fourth web space of her left hand with the pre-operative markings of incisions of on both dorsal and palmar sides (A,B). Intraoperative dissection of the double winged flap $(\mathrm{C})$. The interdigital and webl spaces were successfully reconstructed without skin after $8 \mathrm{~m}$ follow-up (D,E,F). 


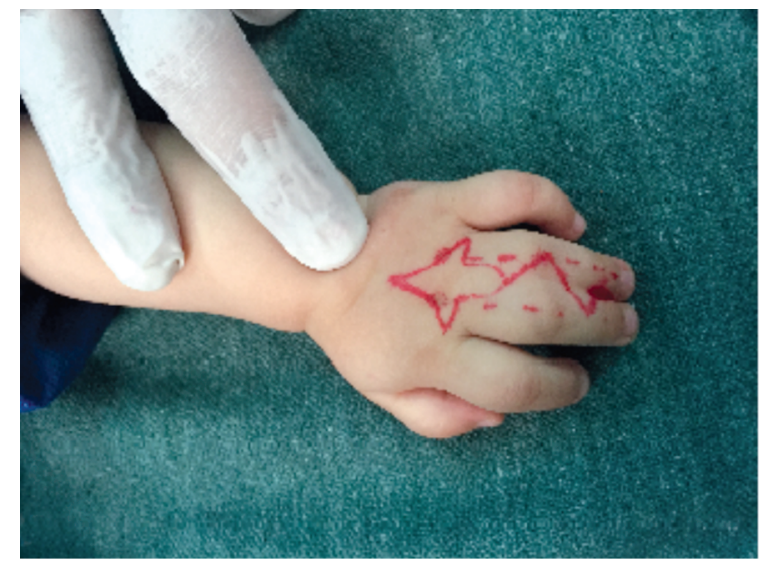

(A)

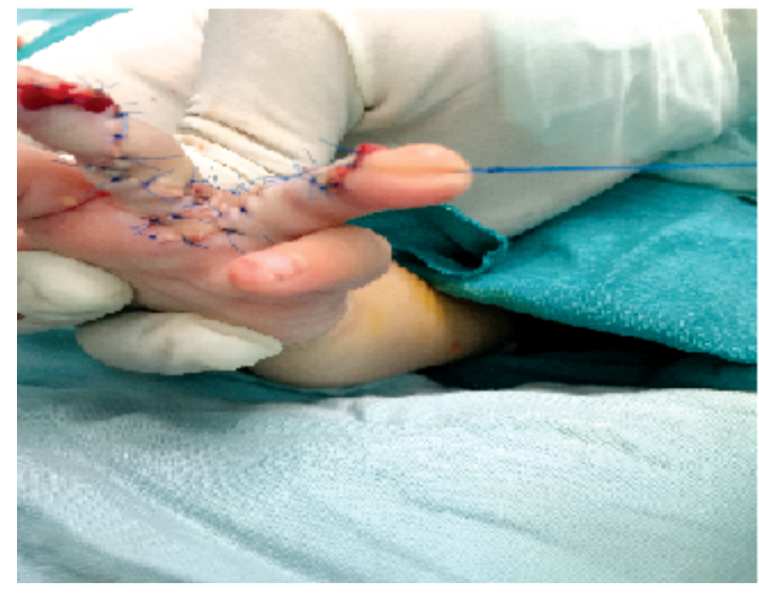

(C)

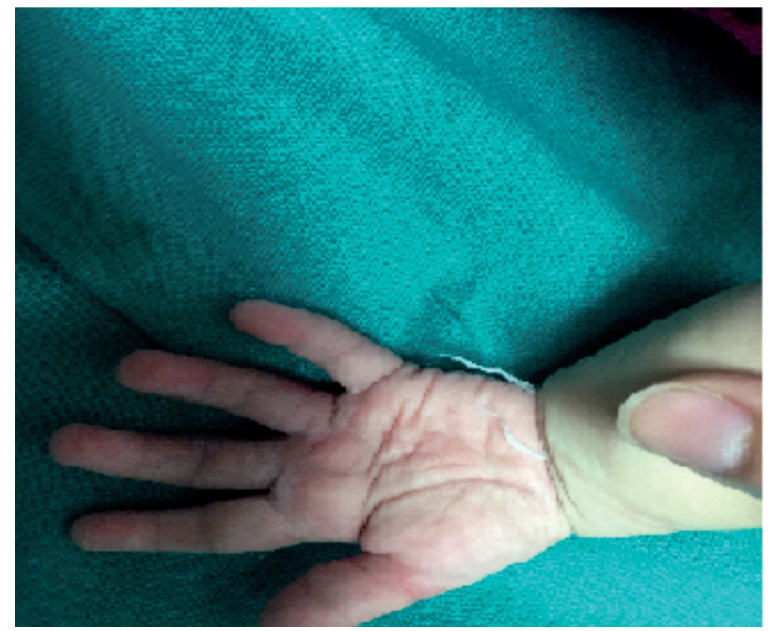

(E)

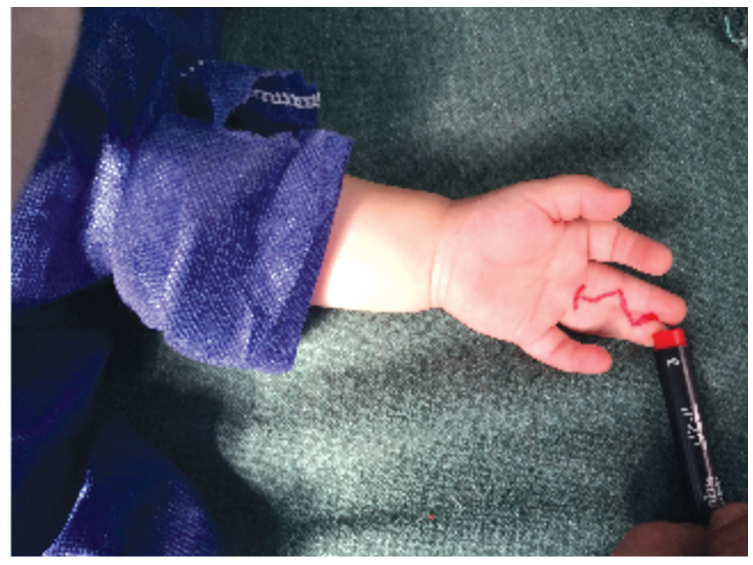

(B)

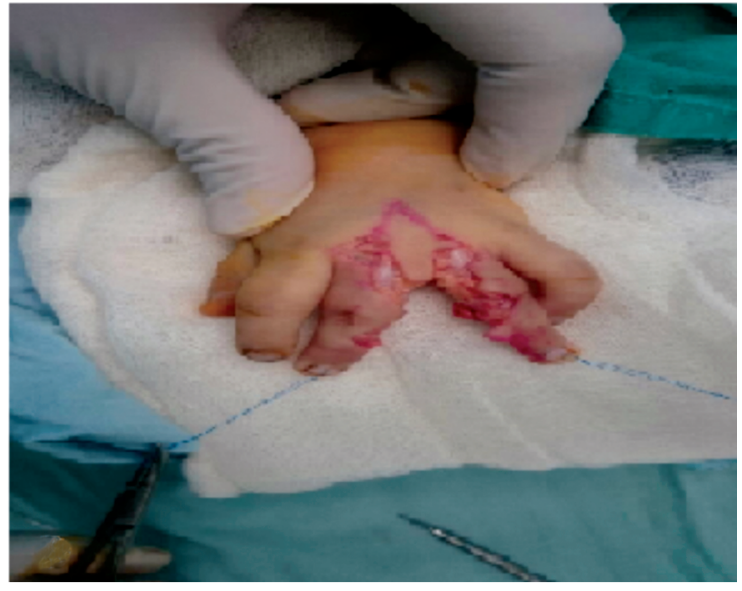

(D)

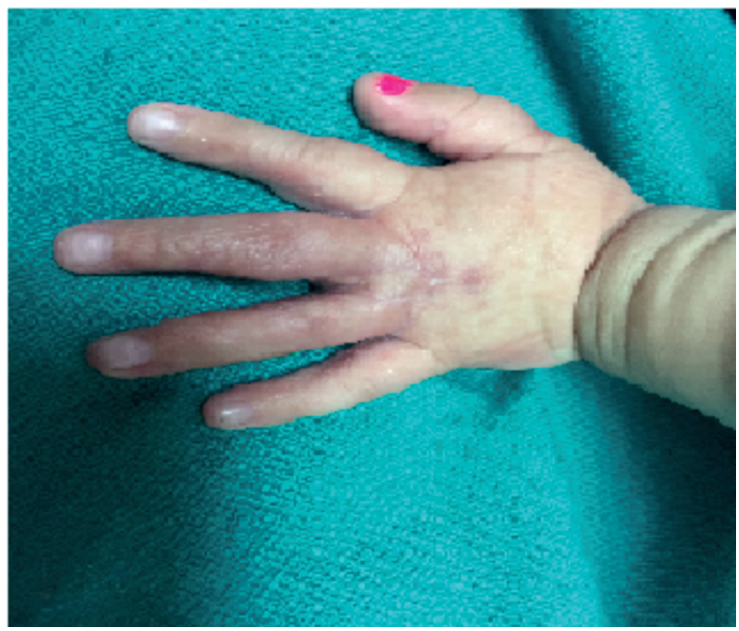

(F)

Fig. (6): Case 4: A 9 months-old girl with left incomplete simple congenital syndactyly in the third web space with the preoperative markings of incisions of on both dorsal and palmar sides (A,B). Intraoperative dissection and in-setting of the double winged flap (C,D). After 18 months post-operative follow-up period with a satisfactory clinical outcome, with cosmetically normal web space and normal function (E,F). 


\section{DISCUSSION}

In congenital syndactyly, the goal of correction is to establish a web that is deep, less contracted, and normal in appearance. Many techniques for syndactyly release have been described over the years. Most authors have regarded the dorsal skin as a good donor for the creation of a normal web space because of its dorsal origin [18]. Marios et al., [19] advised a dorsal rectangular flap for web coverage, combined with two volar triangular, laterally based flaps. D'Arcangelo et al., [20] described a technique involving the creation of a dorsal omega-shaped flap and a palmar anchor forming 2 lateral-palmar flaps. Glicenstein et al., [21] draw a T-shaped incision on the palmar side with a broad dorsal flap to reconstruct web space. Although all these dorsal flaps can create a wide enough inter-digital commissure with an optimal curve, skin grafting is still required to resurface the remaining skin defect at the base of the fingers along the lateral wall of the commissure where skin is usually deficient in the standard technique of syndactyly release. The use of skin grafts is associated with numerous problems, including web creep, graft loss, skin of different color, hyperpigmentation, hair growth, hypertrophic scarring and secondary graft contraction [22]. In addition, the use of skin grafts increases the operative time, and thus maximizing anesthetic exposure in this age group. Recently, numerous studies have reported that multiple general anesthetics impair neurologic development in infants and young children and have a dose-dependent neurodegenerative effect [23].

Excessive skin on the dorsum of the hand can be easily advanced distally as a perforator pedicled flap and form a new web space with matching texture, thickness and color, this flap can be well perfused by the underlying fascia pedicle and dorsal metacarpal artery [24]. Ekerot [25] reported a technique using a dorsal flap from the syndactylized proximal phalanges to substitute commissural skin grafts. After that, a variety of dorsal flaps have been described to repair syndactyly without skin grafts [26,27].

An island $\mathrm{V}-\mathrm{Y}$ advancement flap based on the direct cutaneous branch of the dorsal metacarpal artery, facilitating a graft-free web reconstruction in syndactyly, has been reported [24]. Subsequently, use of the dorsal metacarpal artery flap as an elliptical transposition flap for web reconstruction has been developed [28]. Such use may not achieve a comfortable commissure as the web configuration is not elliptical and results in a slightly longer dorsal hand scar extending to the web apex dorsally. Meanwhile, this flap also is used as a pentagonal island flap for web reconstruction, which is configured by a rectangle distally and a triangle proximally. This technique may provide an easy way to close the dorsal incision, as well as graftless resurface of the web space. However, it may not achieve a satisfactory web due to the discrepancy in web configuration and may have disadvantages similar to those of a local rectangular flap. Besides, conspicuous scars or even hypertrophic scars on the dorsal hand also are common in this series [14]. Recently, a dorsal omega flap [20] was introduced for web reconstruction with good outcomes. However, skin grafts around the web space may not be completely avoided, which may increase the risk of scar contracture in the long term.

The web space after syndactyly separation is left hexagonal on both the dorsal and palmar sides with triangular defects on the bases of both sidewalls of the involved digits [16]. In the current study, to optimize the outcomes of syndactyly correction, a local dorsal double winged metacarpal artery advancement flap designed in a hexagonal shape was used to reconstruct 14 web spaces in ten paediatric patients. Adding two wings on each side of the hexagonal flap was designed to cover these triangular defects properly and to provide a nearly normal configuration for interdigital web space, which is wider distally, tapers off proximally and slopes at a $35-45^{\circ}$ angle from the proximaldorsal to the distal-palmar plane [29].

The dorsal skin of the hand near the web space where this double-wing flap is located is the best material to reconstruct the web space. It has a good elastic structure similar to the normal web space and can offer a more aesthetic and anatomic correction of the web [16]. In addition, the flap is a pedicle flap, perfused by the underlying fascia pedicle between the metacarpal heads and dorsal metacarpal artery giving it a rich blood supply, which makes it less prone to necrosis. Furthermore, there is minimal scarring after primary closure of the donor site on the dorsum of the hand.

All the defects on the proximal sidewall of digits in our study received sufficient coverage from the flap wings. No skin graft was needed in any case. No one in our patients reported one of the early post-operative complications. This may be partially attributable to the capture of graft failure as an additional complication in grafting procedures; whereas this complication is necessarily excluded from this study as a flap-only reconstruction was used in all cases, and thus, flap necrosis 
and infection remain the only reported early complications.

During the follow-up period which was (range, 12-28 months; mean, 21.4 months), associated complications including secondary contracture and hyperpigmentation were not observed in any of the cases. As the longest follow-up time was only 28 months, we could not evaluate the incidence of web creep in the long run. Revision surgery, was not required in any case. Overall, all patients achieved good function, and cosmetic results following a single surgery. The parents were especially satisfied with the result that their kids stopped hiding the inflicted hand, which may be seen as an indication of patient satisfaction.

\section{Conclusion:}

In conclusion, based on the results of our study, the key to successful syndactyly surgery is appropriate surgical design, caution in handling tissues gently and promoting healing without infection.

The dorsal double winged metacarpal artery advancement flap is a simple, rapid and safe technique for web reconstruction in congenital simple syndactyly without skin grafts associated complications.

\section{REFERENCES}

1- Sullivan M.A. and Adkinson J.M.: A Systematic Review and Comparison of Outcomes Following Simple Syndactyly Reconstruction With Skin Grafts or a Dorsal Metacarpal Advancement Flap. J. Hand. Surg. Am., 42 (1): 34, 2017.

2- Schwabe G.C. and Mundlos S.: Genetics of Congenital Hand Anomalies. Handchirurgie. Mikrochirurgie. Plast. Chir., 36: 85, 2004.

3- Malik S.: Syndactyly: Phenotypes, genetics and current classification. Eur. J. Hum. Genet., 20 (8): 817, 2012.

4- Loréa P. and Coessens B.C.: Evolution of surgical techniques for skin releases in the treatment of simple congenital syndactyly: A review. Eur. J. Plast. Surg., 24 (6): $275,2001$.

5- Bauer T.B., Tondra J.M. and Trusler H.M.: Technical modification in repair of syndactylism. Plast. Reconstr. Surg., 17 (5): 385, 1956.

6- Cronin T.D.: Syndactylism: Results of zig-zag incision to prevent post-operative contractors. Plast. Reconstr. Surg., 18 (6): 460, 1956.

7- Keret D. and Ger E.: Evaluation of a uniform operative technique to treat syndactyly. J. Hand Surg. Am., 12 (5): 727-9, 1987.

8- Teoh L.C. and Lee J.Y.L.: Dorsal pentagonal island flap: A technique of web reconstruction for syndactyly that facilitates direct closure. Hand Surg., 9 (2): 245, 2004.
9- Deunk J., Nicolai J.P.A. and Hamburg S.M.: Long-term results of syndactyly correction: Full-thickness versus split-thickness skin grafts. J. Hand Surg. Am., 28 (2): $125,2003$.

10- Ni F., Mao H., Yang X., et al.: The Use of an Hourglass Dorsal Advancement Flap Without Skin Graft for Congenital Syndactyly. J. Hand Surg. Am., 40 (9): 1748, 2015.

11- Magdi Sherif M.V.Y.: Dorsal metacarpal flap: A new technique for the correction of syndactyly without skin graft. Plast. Reconstr. Surg., 101 (7): 1861, 1998.

12- Brennen M.D. and Fogarty B.J.: Island flap reconstruction of the web space in congenital incomplete syndactyly. J. Hand Surg. Am., 29 (4): 377, 2004.

13- Hsu V.M., Smartt J.M. and Chang B.: The modified V-Y dorsal metacarpal flap for repair of syndactyly without skin graft. Plast. Reconstr. Surg., 125 (1): 225, 2010.

14- Gao W., Yan H., Zhang F., Jiang L., Wang A., Yang J., et al.: Dorsal pentagonal local flap: A new technique of web reconstruction for syndactyly without skin graft. Aesthetic Plast. Surg., 35 (4): 530, 2011.

15- Niranjan N.S., Azad S.M., Fleming A.N.M. and Liew S.H.: Long-term results of primary syndactyly correction by the trilobed flap technique. Br. J. Plast. Surg., 58 (1): 14, 2005.

16- Liu J., Zheng H., Chen Z., Dai X., Schilling A.F. and Machens H.G.: Dorsal plane-shaped advancement flap for the reconstruction of web space in syndactyly without skin grafting: A preliminary report. J. Plast. Reconstr. Aesthetic. Surg., 68 (11): 167, 2015.

17- Arrunategui G., Wada A., Tuma Jr. P., Ferreira M.C., Friedhofer H.: Rectangular flaps technique for treatment of congenital hand syndactyly. Rev. Hosp. Clin. Fac. Med. Sao Paulo, 54 (4): 107-10, 2005.

18- Shin A.Y., Oberg K.C., Wood V.E., Dao K.D. and Billings A.: Surgical Treatment of Congenital Syndactyly of the Hand. Journal of the American Academy of Orthopaedic Surgeons, 12 (1), 39, 2016.

19- Marios M.D., Lykissas M.G., Soucacos P.N., Korompilias A.V. and Beris A.E.: Congenital syndactyly: Outcome of surgical treatment in 131 webs. Tech. Hand Up Extrem. Surg., 14: 2, 2010.

20- D'arcangelo M., Gilbert A. and Pirrello R.: Correction of Syndactyly using a Dorsal Omega Flap and Two Lateral and Volar Flaps: A long-term review. J. Hand Surg. Br., 21 (3): 320, 1996.

21- Glicenstein J. [What's new in syndactyly?] Ann. Chir. Plast. Esthet., 43: 611, 1998.

22- Lumenta D.B., Kitzinger H.B., Beck H. and Frey M.: Long-term outcomes of web creep, scar quality, and function after simple syndactyly surgical treatment. J. Hand Surg. Am., 35 (8): 1323, 2010.

23- Jevtovic-Todorovic V.: Anesthesia and the developing brain: Are we getting closer to understanding the truth? Vol. 24, Current Opinion in Anaesthesiology, 24: 395, 2011.

24- Yildirim C., Sentürk S., Keklikçi K. and Akmaz I.: Correction of syndactyly using a dorsal separated V-Y advancement flap and a volar triangular flap in adults. Ann. Plast. Surg., 67 (4): 357, 2011. 
25- Ekerot L.: Syndactyly correction without skin-grafting. J. Hand Surg. British Eur. Vol., 21 (3): 330, 1996.

26- Sharma R.K., Tuli P., Makkar S.S. and Parashar A.: Endof-Skin grafts in syndactyly release: Description of a new flap for web space resurfacing and primary closure of finger defects. Hand, 4 (1): 29, 2009.

27- Matsumine H., Yoshinaga Y., Fujiwara O., Sasaki R., Takeuchi M. and Sakurai H.: Improved "bell-bottom" flap surgical technique for syndactyly without skin graft. Plastic and Reconstructive Surgery, 128 (5): 504, 2011.

28- Aydin A. and Ozden B.C.: Dorsal Metacarpal Island Flap in Syndactyly Treatment. Ann. Plast. Surg., 52 (1): 438, 2003.

29- Tan O., Atik B. and Ergen D.: Versatile use of the VMplasty for reconstruction of the web space. Ann. Plast. Surg., 55 (6): 623, 2005. 